\title{
ANÁLISE DO PROCESSO DE REESTRUTURAÇÃO DO SETOR ELÉTRICO BRASILEIRO
}

\section{RESUMO}

\author{
L. C. B. GUERRA, S. C. A. SILVA \\ lenin.cavalcanti@ifrn.edu.br
}

O presente artigo analisa o processo de reestruturação e a expansão do setor elétrico brasileiro entre os anos de 1995 a 2014, evidenciando os principais desafios para o crescimento continuado do setor elétrico nacional. Para tanto, utilizou como procedimento metodológico o método das narrativas para construção das relações entre os eventos ocorridos no período em análise, a partir da análise de documentos do Ministério das Minas e Energia, como o Balanço Energético Nacional (BEN), e pesquisas acadêmicas cujo objeto foi o setor elétrico, como as de Castro et al (2013), Costellini e Holanda (2014) e Bajay (2015). Em linhas gerais, foi observado que os principais desafios para o setor elétrico durante o período foi a questão regulatória, que passou e continua em processo de ajustes e planejamento de longo prazo. Por fim, pode-se concluir que os modelos implantados no processo de reestruturação do setor elétrico nacional alcançaram resultados significativos e de avanço ao segmento elétrico, todavia faz-se necessária continuidade do planejamento mudanças. Alguns pontos positivos contribuíram para o crescimento do setor elétrico, sobretudo a abertura para atuação privada, implantação dos ambientes de contratação regulada e contratação livre, além da implantação em longo prazo para minimizar as incertezas que ainda existem no setor e ampliar a expansão e segurança energética no país.

Palavras-Chaves: políticas públicas, setor elétrico, narrativa.

\begin{abstract}
This article analyzes the process of restructuring and expansion of the Brazilian electricity sector between 1995 and 2014, highlighting the main challenges for the continuous growth of the national electricity sector. For this, was used as methodological procedure narrative method for the construction of relations between events under analysis, based on the analysis of documents of the Ministry of Mines and Energy, such as the National Energy Balance (BEN), and academic researches about electric sector, such as Castro and others (2013), Costellini and Holanda (2014) and Bajay (2015). In general terms, it was noted that the main challenges for the electric sector during the period to a regulatory problem, which has passed and continues in the process of adjustments and long-term planning. Finally, it can be concluded that the models implemented and not the restructuring process of the national electric sector have achieved significant results and advance to the electric segment, however it is done. Some good points contribute to the growth of the electricity sector, the opening up to private operation, the implementation of regulated contracting and free contracting environments, as well as the long-term implementation to minimize the uncertainties that no sector still exists and to enlarge energy security.
\end{abstract}

Keywords: policies, electricity sector, narrative. 


\section{INTRODUÇÃO}

A energia elétrica é um importante componente para a atividade econômica, sendo insumo de vários setores da economia, como a indústria, serviços, telecomunicação, etc, além de ser essencial para a organização social. Observa-se que a cada dia os planejamentos energéticos dos países na promoção da estrutura e segurança da oferta de energia elétrica tem sido incrementados, de forma a atender a demanda crescente de firmas e consumidores por eletricidade.

Ademais, a energia tem sido um tema presente internacionalmente devido à questão do desenvolvimento sustentável e da eficiência na utilização dos recursos disponíveis no planeta. No Brasil o setor elétrico é regulado pelo Governo Federal, que desde o ano de 2004 lançou as bases de um novo modelo institucional e regulatório para o setor.

Em termos institucionais, esse novo modelo definiu a criação de uma entidade responsável por estudos relacionados ao planejamento energético, a Empresa de Pesquisa Energética (EPE), um órgão com a função de avaliar permanentemente a segurança do suprimento de energia elétrica, o Comitê de Monitoramento do Setor Elétrico (CMSE) e uma instituição para celebrar os contratos de comercialização de energia elétrica no Sistema Interligado Nacional (SIN), a Câmara de Comercialização de Energia Elétrica (CCEE).

Além destes órgão destaca-se a atuação da Agência Nacional de Energia Elétrica (ANEEL), agência reguladora independente que visa preservar o equilíbrio econômico e financeiro dos agentes, protegendo os interesses dos consumidores em relação aos custos da energia, e do Operador Nacional do Sistema Elétrico (ONS), entidade de direito privado, sob a forma de associação civil, sem fins lucrativos, responsável por coordenar e controlar a operação das instalações de geração e de transmissão do SIN.

Frente a essa estrutura institucional, é importante que o Governo articule e implante ações que desenvolvam esse setor. Goldemberg e Moreira (2005) afirmam a necessidade de haver políticas que proporcionem condições especiais de mão de obra, tecnologias e equipamentos para o desenvolvimento do setor energético. Estes autores enfatizam a imprescindível participação do setor público para esse alcance, visto destacarem a necessidade de políticas públicas para administrar o conjunto de vantagens e riscos, além de eficiente alocação financeira de recursos, tendo em vista que existe uma alta participação da iniciativa privada na produção de energia nacional.

Percebe-se que no Brasil, as iniciativas, por meio de reformas estruturais e políticas, promoveram no decorrer dos últimos anos maior confiabilidade e segurança a matriz elétrica brasileira. O país teve em sua base histórica de geração de energia a dependência pela fonte hidráulica, contudo a matriz de energia elétrica do país passou por diversificação reduzindo essa participação das fontes hídricas e tornando a matriz de geração elétrica mais dinâmica e segura. No ano de 2005, a participação da fonte hidráulica representava 74,6\% da matriz de geração, já no ano de 2014 reduziu-se para 65,2\%, com a inserção, no mesmo período, de novas fontes renováveis. É importante nesse segmento o planejamento para garantir a expansão e sustentabilidade da matriz, uma vez que a segurança energética também é componente basilar para a atração de investimentos e, por conseguinte do desenvolvimento.

Diante disso, o atual trabalho tem por objetivo analisar o processo de reestruturação e expansão do setor elétrico brasileiro entre os anos de 1995 a 2014. Com vistas a alcançar tal objetivo, adota-se quatro eixos de objetivos específicos, a saber: i) descrever o processo de reestruturação do setor elétrico no que tange as ações, medidas e marcos regulatórios; ii) formular relações entre os eventos do processo de reestruturação do setor elétrico ocorridos nos anos de 1995 até 2004, no ano de 2004, e os anos seguintes até 2014; iii) levantar dados da evolução e diversificação da matriz elétrica nacional; iv) construir o cenário elétrico para o período em análise. Através dos objetivos apresentados, pretende-se constatar se as estratégias do setor público nos últimos anos têm sido eficientes para assegurar a expansão contínua do setor elétrico. 
Dessa forma, o tema proposto para estudo apresenta relevância na medida em que se apresenta a dinâmica do setor elétrico brasileiro, com as políticas e estratégias adotadas para o crescimento e desenvolvimento do setor de energia elétrica, sendo esse um relevante insumo para diversas atividades econômicas e para o bem-estar social.

\section{REFERENCIAL TEÓRICO}

\section{Administração Pública}

A administração pública historicamente se caracterizou por uma evolução de preponderância entre os modelos patrimonialista, burocrática e gerencial. No Brasil, o modelo patrimonialista foi adotado até meados da década de 1930, quando emergiu o modelo burocrático, mas devido inadequações tal modelo sofreu algumas tentativas de reformas ao longo dos anos. A partir da década de 1990, com a redefinição no papel do Estado, foi sendo consolidada no país uma administração mais voltada para o modelo gerencial, onde a eficiência, eficácia e efetividade das ações do Estado passaram a ser mais eminentemente buscadas.

Segundo Klering et al (2010), o modelo patrimonialista tinha como características predominantes uma indefinição entre o que seria de interesse público e de interesse privado por parte dos gestores, além da prática bastante marcada do nepotismo e da corrupção. Os autores em tela frisam que diante da necessidade de se garantir a defesa da sociedade mediante o poder soberano do patrimonialismo, contrapondo-se a esse com a separação do que é público e privado, o modelo burocrático passou a ser adotado no país na década de 1930, onde aspectos como controle de processos e decisões, hierarquias e formalismos passaram a ser incorporados na administração pública.

Já no que tange a administração gerencial, ela surge como uma necessidade de flexibilizar o modelo burocrático que apresentava várias disfunções quanto ao controle do Estado. Diversas tentativas de melhoras foram realizadas, seja por meio da criação, ou até mesmo extinção, de órgãos públicos ou pela composição de novas estruturas que tinham por objetivo reduzir, mas não anular, a rigidez burocrática. (KLERING et al, 2010).

Quanto às características do modelo gerencial, Dagnino (2012) chama a atenção para as técnicas de gestão que o mesmo dissemina, uma dessas técnicas seria o planejamento estratégico governamental, que visa a eficiência e eficácia da gestão. No Brasil as iniciativas de implantação do planejamento estratégico foram realizadas em diversos segmentos, a utilização dessa ferramenta, seja no curto ou no longo prazo, possibilita ao setor público do país uma gestão compromissada com a eficiência de serviços ao longo do tempo.

\section{Planejamento Estratégico Governamental e Políticas Públicas}

Segundo Toni (2014), o Planejamento Estratégico Governamental (PEG) expande o conceito das teorias de planejamento que partem da análise da eficiência e eficácia, visto que além de maximizar esses conceitos na gestão, o PEG também se caracteriza por sendo um processo político participativo que se configura em um projeto estratégico para a sociedade.

No Brasil, alguns fatores promoveram execuções de ações de planejamento estratégico governamental como, por exemplo, o avanço do crescimento e desenvolvimento econômico que condicionou, e condiciona, a exigência de medidas de planejamento. Além disso, a atuação e implementação de ações e de políticas públicas em setores estratégicos como os de produção e serviços também promovem esse desenvolvimento. (OLIVEIRA, 2006) 
Concernente às políticas públicas, é basilar compreender a conceituação e dinâmica de atuação das mesmas na gestão pública. Teixeira (2002) conceitua o termo como sendo "diretrizes, princípios norteadores de ação do poder público, regras e procedimentos para as relações entre poder público e sociedade, mediações entre atores da sociedade e do Estado.” (TEIXEIRA, 2002, p. 2).

Assim, as políticas públicas se configuram como um conjunto de formulação de propostas ou de decisões e ações que são tomadas em resposta às demandas de uma determinada área, como saúde, educação ou infraestrutura. De acordo com Teixeira (2002), podem ser decididas de forma discricionária por organizações públicas ou ainda pela combinação de esforços com a sociedade.

Rua (2012) alerta para a necessidade de diferenciar o conceito de política pública com o de decisão política, a primeira comumente representa além da decisão, pois as políticas públicas requerem a existência de várias ações que sejam selecionadas de forma estratégica para que adiante subsidiem implementações de ações das decisões tomadas, ao contrário da decisão política que apenas corresponde a uma escolha a ser feita diante de diversas alternativas.

No que tange às ações, políticas públicas, planejamento e regulação específicos do setor elétrico, tema do atual estudo, é relevante observar as relações existentes entre estes aspectos apontados anteriormente na gestão do setor elétrico. Sobretudo pelo fato de que no Brasil esse setor passou por diversas reestruturações na busca por sustentabilidade, e para isso medidas de planejamento e políticas públicas foram implantadas no decorrer dos anos. Nesse tocante, alguns autores analisaram a condução desse processo no transcorrer das estruturações implementadas no segmento, verificando a maneira como ocorreu essa dinâmica.

Chiganer et al (2015) pontuaram que o Brasil desde a década de 1990 tem reformulado o setor energético, inserindo mudanças importantes como a abertura para a participação do setor privado nos investimentos de expansão, além da criação de agências reguladoras balanceando os interesses das empresas e do consumidor final e implementação de políticas públicas que assegurem o crescimento consolidado desse setor.

Kessler (2006) realizou uma leitura do setor elétrico brasileiro identificando suas transformações e organização. $\mathrm{O}$ autor chama a atenção para a regulação econômica baseada em subsídios para tornar o mercado de energia elétrica atrativo à iniciativa privada, além das incertezas regulatórias que surgiram após o projeto RE-SEB. Enfatiza que tais medidas não alcançaram as metas estabelecidas na tentativa de reestruturação, que seria o aumento da eficiência e qualidade do serviço, além da modicidade tarifária.

Concomitante, Correia et al (2006) buscaram analisar os ambientes comerciais e institucionais do Brasil após processos de reestruturação do setor elétrico. Os autores frisam que embora tenha alcançado avanços, o modelo institucional para a indústria elétrica nacional necessita de ajustes para mitigar as incertezas, que segundo eles ainda existem no setor, sobretudo pela regulação não apenas do segmento elétrico como de outros setores que com ele se relacionam.

Diante disso, percebe-se que alguns estudos trazem a temática da análise dos termos em que se deram as medidas de mudanças na estrutura do mercado de atuação da indústria elétrica. Em certo ponto tais estudos apontam que alguns objetivos traçados na elaboração dessas alterações institucionais e/ ou estruturais, não foram totalmente alcançados. É importante ainda estabelecer relações de impacto na expansão do setor de acordo com os diferentes períodos e suas nuances, além de verificar aspectos como o planejamento e decorrências das alterações da regulação elétrica.

Nesse tocante, Bajay (2015), que investigou o papel do planejamento no setor energético brasileiro, apontou que apenas a partir de 2001, após crise que culminou o racionamento de energia elétrica, o planejamento nesse segmento se tornou mais robusto, com a percepção de que para garantir a expansão e operação do sistema era necessário pensar em ações de longo prazo. $\mathrm{O}$ autor chama a atenção para desafios do setor que demanda a continuidade futura e permanente das ações de planejamento adotadas pelo governo nos últimos anos. 
Percebe-se que tais desafios apontados permanecem atuais, como descrito por Costellini e Holanda (2014): há obstáculos ainda presentes e merecem ações de planejamento para que sejam sanadas as dificuldades. As autoras em seu trabalho descrevem os impactos que a regulação após 2004 trouxe para as concessionárias de energia elétrica, ocasionando sérios problemas nos fluxos de caixas de algumas empresas.

Dessa forma, constata-se que essa temática permanece relevante de análise atualmente, acrescentando as alterações que surgiram no segmento no decorrer dos últimos anos, bem como os impactos que tais trouxeram sobre a expansão do setor elétrico.

\section{METODOLOGIA}

Com intuito de analisar o processo de reestruturação do setor elétrico, bem como sua expansão no período em análise, utiliza-se como metodologia pesquisa qualitativa do tipo descritiva, fazendo uso do método das narrativas analíticas e do método documental com uso de dados secundários.

Para a análise do processo de reestruturação do setor elétrico, se optou por analisar os dados pelo método das narrativas analíticas, por esse viabilizar formulação dos distintos eventos que compõem a experiência em estudo, além de proporcionar a possibilidade de constituir relações entre os eventos que serão relatados, e de permitir a construção de questões passíveis de investigação. (GUERRA, 2015)

Ou seja, tal método permite a descrição de fatos históricos relevantes para explicar eventos importantes ocorridos no segmento do setor elétrico. Segundo Guerra (2015), os eventos são elementos que fazem parte do relato que se propõe a descrever. Assim, a partir dessa análise pode-se sistematizar e evidenciar os principais fatos e eventos ocorridos durante o processo de reestruturação do setor elétrico.

Ademais, nessa construção existe entre os eventos o episódio, que de acordo com Gottems (2010, p. 64), também pode ser denominado de evento central e é representado pelo "conjunto de eventos diretamente e intimamente relacionado ao processo de interesse substancial".

Diante disso, o atual estudo adotará como fluxo de eventos, para se construir e analisar a relação estabelecida entre os eventos no processo de reestruturação do setor elétrico, conforme demonstração da Figura 1.

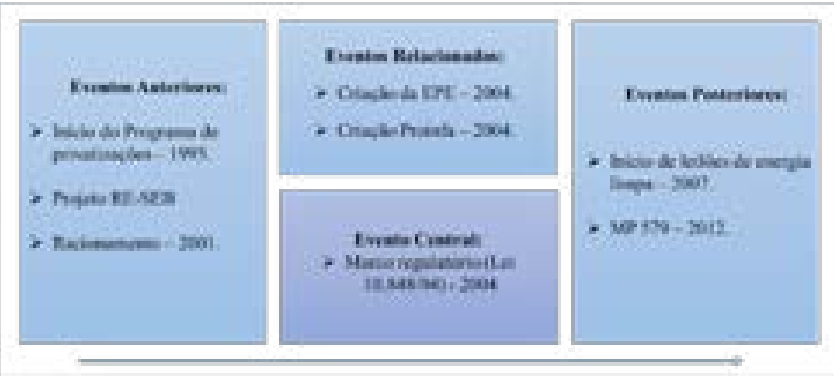

Figura i: Estrutura do método de análise. Fonte: Adaptado de Guerra(2015).

No que tange a análise da expansão do setor elétrico no período de 1995 a 2014, utilizou-se a análise documental com utilização de dados secundários, a partir de relatórios da Empresa de Pesquisa Energética, Operador Nacional do Sistema Elétrico, Câmara de Comercialização de Energia Elétrica, e do Balanço Energético Nacional (BEN), todos vinculados ao Ministério de Minas e Energia, além de pesquisas acadêmicas cujo objeto foi o setor elétrico, como as de Srour (2005), Kessler (2006), Castro e Bueno (2007) Silva (2011), Castro et al (2013), Costellini e Holanda (2014) e Bajay (2015), com o objetivo de mapear variáveis que possam indicar a evolução do setor, entre elas: participação das fontes renováveis na matriz elétrica e indicadores de oferta e consumo de energia. 


\section{REESTRUTURAÇÃO DO SETOR ELÉTRICO BRASILEIRO: PRINCIPAIS EVENTOS, AÇÕES E POLÍTICAS}

Em linhas gerais, até meados da década de 1950 o setor elétrico brasileiro contava com a participação de empresas privadas, que diante da incapacidade de recursos ou apreensão pelo risco de retorno do investimento na área energética provocou acentuada redução da qualidade do serviço elétrico nacional. Diante disso, foram adotadas diversas medidas e criados vários e órgãos culminando em uma elevada participação do Estado no setor; essa etapa, marcada por forte estatização, perdurou até década de 1990 quando o país enfrentou grave crise energética. Após reestruturação do setor elétrico, o mesmo passou a contar novamente com atuação de agentes privados, além do regime competitivo de mercado onde o Estado assumiu a posição de regulador. (SILVA, 2011)

Durante o período de estatização do setor elétrico, onde o setor público era responsável pela expansão do sistema de geração, transmissão e distribuição, "as empresas do Governo Federal produziam cerca de 60\% da geração do país e as dos Governos Estaduais faziam a distribuição, sendo algumas delas também geradoras de energia". (CHIGANER et al, 2015, p. 04) .

Essa participação do Estado no setor elétrico foi expressamente reduzida ao longo dos anos, devido algumas transformações de magnitude estrutural, institucional e legal. Basicamente, para este estudo será considerado para análise os modelos do setor elétrico após a estatização em meados da década de 1950. Sendo assim, consideram-se três modelos distintos, sendo o primeiro anterior a 1995, o segundo momento até o ano de 2003 e o terceiro e atual modelo a partir de 2004, esse contexto será apresentado nas seções a seguir.

4.1 Eventos anteriores: das privatizações de 1995 ao racionamento de energia de 2001

Na década de 1980, o Brasil passou por uma fase de fraco desempenho econômico comparado às décadas anteriores. O país enfrentou dificuldades arcando com uma crise econômica, queda da atividade industrial, retração das importações, alta inflação, instabilidade monetária, e escassez de recursos públicos para investimento. (OLIVEIRA, 2012)

Nesse cenário, as empresas estatais eram responsáveis pela formulação de políticas setoriais, além de que produziam e comercializavam bens e proporcionavam serviços públicos e de infraestrutura. A regulação do setor elétrico, por exemplo, era conduzida de maneira simples pelo Conselho Nacional do Petróleo e pelo Departamento de Águas e Energia.

Além disso, o financiamento era através de recursos públicos, as empresas predominantemente estatais, sem existência de competição e formado por empresas verticalizadas, consumidores cativos, mercado regulado, tarifas reguladas em todos os segmentos, planejamento determinativo pelo Grupo Coordenador do Planejamento dos Sistemas Elétricos - GCPS, contratação 100\% a mercado, e sobras / déficits do balanço energético eram rateados entre compradores. (CCEE, 2015)

Diante desse contexto e do momento econômico nacional, o setor elétrico enfrentou momento de estagnação atingindo ápice da crise na década de 1990. De acordo com Silva (2011), tal fato se deu, entre outros fatores, devido à crise econômica e pela insuficiente capacidade de investimento do setor público para as expansões necessárias.

Concomitante, no ano de 1995 foi criada a Lei 8987/95, que previa a concessão e permissão da prestação de serviços públicos abrindo essas atividades à participação da iniciativa privada que fazia parte do Programa Nacional de Desestatização - PND. A aderência por parte do Governo brasileiro ao programa de permissão da atuação da iniciativa privada na prestação dos serviços públicos, permitiu que algumas áreas contassem com maior investimento. No que tange o setor elétrico, o programa de privatizações foi um passo inicial em direção a necessidade de reestruturar o setor. (CHIGANER et al, 2015) 
As primeiras empresas elétricas foram privatizadas no ano de 1995, contudo apenas em 1996 foi implantada por meio da Lei 9.427 a Agência Nacional de Energia Elétrica (ANEEL), órgão regulador que fiscalizaria as etapas de geração, transmissão, distribuição e comercialização do setor elétrico. A falha nesse processo, segundo Chiganer et al (2015), foi de os órgãos fiscalizadores só terem sido criados após início das primeiras privatizações, quando os mesmos deveriam já estar consolidados para acompanhar todo o processo.

Concernente a Agência Nacional de Energia Elétrica, além de fiscalizar as etapas mencionadas, também tem por responsabilidade as licitações das concessões e celebração de contratos de concessão do setor, promovendo ainda a introdução de competição na exploração do serviço de energia elétrica mantendo a qualidade do mesmo, e assim "proporcionar condições favoráveis para que o mercado de energia elétrica se desenvolva com equilíbrio entre os agentes e em benefício da sociedade". (ANEEL, 2015)

Da mesma maneira que a implantação da Aneel se deu de maneira lenta, a instituição de um órgão que tivesse autonomia para coordenar e reduzir falhas de mercado e regularizar o mercado atacadista do setor também foi tardio. Apenas no ano de 1998 o Ministério de Minas e Energia (MME) decretou as características comerciais do setor elétrico nacional, definindo assim os predicados e papel do órgão responsável por coordenar o setor, o Operador Nacional do Sistema Elétrico Brasileiro (ONS). (CORREIA et al, 2006)

O mesmo foi instituído pela Lei 9.648/98, tem por responsabilidade "coordenação e controle da operação das instalações de geração e transmissão de energia elétrica no Sistema Interligado Nacional, sob a fiscalização e regulação da Agência Nacional de Energia Elétrica". O mesmo se configura como órgão estratégico para o setor, pois sua atuação de forma sistêmica proporciona gestão dos recursos energéticos do país. O ONS se tornou o responsável para promover a segurança no suprimento de energia, bem como a otimização econômica da operação do setor. (ONS, 2015)

O Operador Nacional do Sistema Elétrico, foi criado a partir o projeto formulado para reestruturar o setor, que contou com a consultoria Coopers \& Lybrand contratada pelo Brasil para elaborar "proposta de um modelo estrutural que redefinisse o papel do Estado e reorganizasse o conjunto de empresas que formavam o setor elétrico brasileiro". A partir disso, foi originado o Projeto de Reestruturação do Setor Elétrico Brasileiro (RE-SEB), a Coopers \& Lybrand definiu o arcabouço conceitual e institucional do modelo a ser implantado pelo Projeto RE-SEB. (KESSLER, 2006, p. 63)

De acordo com Kessler (2006), o Projeto RE-SEB apresentava como modelo para o setor elétrico nacional semelhanças ao modelo internacional da época, onde o segmento pudesse ter uma organização industrial com existência de mercado competitivo em substituição ao modelo monopolista que predominava.

O novo modelo proposto pelo RE-SEB pretendia:

Garantir a retomada dos investimentos necessários à infraestrutura do setor [...], criar as condicões para a atração do capital privado, introduحir a competição e a busca pela eficiência operacional e administrativa das empresas, criar estrutura institucional que seria responsável pelo controle operacional do sistema e da gestão das empresas concessionárias (agencia reguladora). (KESSLER, 2006, p. 83 e 84)

Em síntese, as principais mudanças desse novo modelo adotado pelo Brasil comparado ao anterior, de acordo com o CCEE (2015), foram: 1) o modelo passou a ser de livre mercado; 2) o financiamento passou a contar com participação de recursos da iniciativa privada; 3) criação do Produtor Independente de Energia (PIE); 4) empresas divididas por atividade de geração e transmissão, distribuição e comercialização; 5) abertura e ênfase na privatização das empresas; 6) competição na geração e comercialização; 7) consumidores livres e cativos; 8) preços livremente negociados na geração 
e comercialização; 9) mercado livre; 10) planejamento indicativo pelo Conselho Nacional de Política Energética (CNPE);11) contratação 85\% do mercado até agosto/2003 e 95\% mercado até dez/2004; 12) sobras/déficits do balanço energético liquidados no MAE.

Com essa nova estrutura, esperava-se que a esfera de atuação elétrica se consolidaria. Contudo, em poucos anos após inserção da iniciativa privada no mercado de energia o setor passou por nova crise, desta feita alcançando seu auge na redução da oferta de energia, provocando no país o programa de racionamento no ano de 2001.

A versão oficial divulgada referente aos motivos que ocasionaram o racionamento energético apresentou como fatores condicionantes a não conclusão da transição do antigo para o novo modelo setorial, somando-se a isso o período de estiagem que provocou baixa nos reservatórios, sendo que a hidráulica era a principal fonte de geração elétrica no país.

No entanto, Srour (2005) aponta que especialistas da área entraram em discordância dessa justificativa do governo, apresentando dados que demonstram a elevação da demanda acima da oferta de energia, representando assim a falta de investimento na geração e transmissão de energia como fatores principais do racionamento.

Diante do exposto, pode-se concluir que o setor elétrico no Brasil evoluiu a partir do implemento de mudanças de reestruturações. Até início da década de 2000 as mudanças visavam a elevação da eficiência por meio da livre competição e capital privado; no entanto, o setor enfrentou nova crise, culminando na necessidade de novas medidas para reestruturar o setor elétrico nacional.

\section{Eventos relacionados: criação da EPE e PROINFA}

Diante das dificuldades enfrentadas pelo modelo RE-SEB, apresentadas anteriormente, uma nova tentativa de reestruturação do setor elétrico foi organizada. O novo modelo tem por marco a Lei 10.848/04 no ano de 2004, concomitante a essa articulação de estruturar um novo modelo para o setor elétrico, alguns eventos relevantes ocorreram.

Seguindo o método das narrativas, Guerra (2015) apresenta os eventos relacionados como sendo aqueles que ocorrem no mesmo período que o evento central e de alguma forma são influenciados por ele. Assim, são apresentados agora os dois principais eventos relacionados, sendo a criação da Empresa de Pesquisa Energética (EPE) e o Programa de Incentivo às Fontes Alternativas de Energia Elétrica (Proinfa).

Com a implantação do novo marco regulatório de 2004, os decretos seguidos deste abrangeram a regulação da comercialização de energia e criação de estratégia de planejamento de longo prazo para o setor. No novo modelo do setor elétrico, entrou em pauta a necessidade de se realizar avaliação permanente da segurança de suprimento de energia e de planejamento energético para o longo prazo. Diante disso, foram criados o Comitê de Monitoramento do Setor Elétrico (CMSE) e a Empresa de Pesquisa Energética (EPE).

O Comitê de Monitoramento do Setor Elétrico foi instituído no ano de 2004, e tem por objetivo “acompanhar e avaliar permanentemente a continuidade e a segurança do suprimento eletro energético em todo o território nacional”. Para isso, o Comitê acompanha o desenvolvimento das atividades de geração, transmissão, distribuição, comercialização, importação e exportação o setor energético. Além disso, realiza avaliação das condições de abastecimento e análise periódica da segurança do abastecimento e atendimento ao mercado energético. (MME, 2015)

Referente ao planejamento executado no segmento elétrico, no modelo antigo, anterior ao RESEB, o planejamento era centralizado e indicativo, tinha por características a existência de subsistemas regionais interligados, instalação de grandes reservatórios de regularização plurianual, operação coordenada 
pela Eletrobrás, estruturação do planejamento setorial centralizado e pesados investimentos estatais. Com a reforma da década de 1990 e a implantação do modelo RE-SEB, o planejamento passou a ser indicativo apenas na geração e determinativo na transmissão, a responsabilidade estava sob o Ministério de Minas e Energia por meio do Comitê Coordenador do Planejamento da Expansão dos Sistemas Elétricos. (CORREIA et al, 2006)

Apenas no novo modelo de 2004 o planejamento estratégico de longo prazo entrou na pauta das discussões de incremento ao setor elétrico: o planejamento passou a ser determinativo e setorial integrado e centralizado pelo Estado através da Empresa de Pesquisa Energética que foi criada para ter a responsabilidade de planejamento centralizado, executando estudos e planejamento planos setoriais para expansão do setor energético. A EPE apresenta por finalidade "prestar serviços na área de estudos e pesquisas destinadas a subsidiar o planejamento do setor energético, tais como energia elétrica, petróleo e gás natural e seus derivados, carvão mineral, fontes energéticas renováveis e eficiência energética, dentre outras". (EPE, 2015)

A criação da EPE pode ser considerada um grande avanço para o segmento, pois apesar de o setor elétrico ser tido como estratégico para economia, uma vez que é insumo da atividade econômica e do bem estar social, ainda não havia sido implementado no país um órgão que centralizasse o planejamento em longo prazo, e por essa via tornar o ambiente desse segmento mais sólido quanto ao futuro, diante disso são perceptíveis as contribuições que a EPE tem trazido para o setor elétrico nacional.

No que tange o Programa de Incentivo às Fontes Alternativas de Energia (Proinfa), o mesmo se configura como um importante incentivo para a promoção do setor energético nacional, na busca da diversificação da matriz elétrica por fontes renováveis, sobretudo a biomassa e eólica, para complementar a geração convencional de eletricidade. Foi criado em 2002, pela publicação da Lei Federal No 10.438 sendo revisada e ajustada através da Lei No. 10.762 em 2003 e finalmente regulamentada através do Decreto No 5.025 de 2004.

Para tanto, o Programa contou com apoio do BNDES, Banco do Brasil, BNB, Banco da Amazônia, ADENE (Agência para Energia), Caixa Econômica Federal, ELETROBRÁS. A ELETROBRÁS como responsável pela contratação dos projetos selecionados pelo Programa pelo prazo de 20 anos e a administração da Conta PROINFA. Esta última é constituída pelos custos da energia gerada, os custos administrativos, financeiros e encargos tributários, a mesma é regulamentada e fiscalizada pela Agência Nacional de Energia Elétrica (ANEEL). (EPE, 2015).

Embora o Proinfa tenha apresentado alguns problemas de conjuntura executiva, ainda assim representou um passo importante para a busca da diversificação da matriz elétrica brasileira, onde foi alcançado resultados considerados para a promoção do crescimento com sustentabilidade, principalmente devido inserção da fonte eólica na matriz de geração elétrica.

\section{Evento central: marco regulatório de 2004}

Conforme apresentação anterior, o novo modelo do setor elétrico foi implantado em 2004 a partir da Lei 10.848. De maneira a compreender a diferenças entre esse e os modelos do setor elétrico descritos anteriormente, na sequência será realizada análise das principais medidas implementadas por leis e decretos até o modelo de 2004. Para melhor entendimento o período de estatização anterior a 1995 será denominado de antigo modelo do setor elétrico; o período de 1995 a 2003 será chamado de modelo RE-SEB, e o período a partir de 2004 de novo modelo.

O financiamento do setor elétrico no antigo modelo era de responsabilidade do setor público, ou seja, cabia ao Estado o investimento na expansão da oferta de maneira a atender a demanda por eletricidade. Após o RE-SEB ocorreu a inserção de capital privado nesse segmento em uma tentativa 
de dinamizar os investimentos do setor por meio da iniciativa privada, mas a atividade elétrica passou a contar também com financiamento através do Banco Nacional do Desenvolvimento. (BNDES, 2015)

Atualmente o BNDES conta com linhas de financiamento destinadas a determinadas atividades e segmentos econômicos. No que tange a área de infraestrutura do setor elétrico, os financiamentos do banco são direcionados a projetos que visam a expansão e/ ou aprimoramento e modernização da geração, transmissão e distribuição de energia elétrica. $O$ apoio também é estendido para iniciativas de utilização das fontes renováveis, além de projetos que buscam promover a eficiência energética. (BNDES, 2015)

Ademais, Correia et al (2006), aponta a relevância dos programas de crédito realizados pelo BNDES em parceira com o Ministério de Minas e Energia (MME), que visa o financiamento de "novos empreendimentos de geração e transmissão de energia elétrica que conta com juros abaixo dos valores de mercado, amortização mais alongada e exigência de capital próprio de apenas 30\%". (CORREIA et al, 2006, p. 623)

Além disso, o autor em tela descreve também o surgimento de outros instrumentos de investimentos que foram desenvolvidos utilizando-se das opções disponíveis no mercado de capitais, como sendo fundos de investimentos e emissão de debêntures, dinamizando ainda mais a disponibilidade de crédito para investimento na expansão do segmento por via de capital privado.

Outro aspecto relevante que evoluiu com as reformas e novos modelos do setor foi a reversão do processo de verticalização das empresas, chamado de desverticalização — no antigo modelo as empresas eram verticalizadas, ou seja, a mesma empresa era responsável pela geração, transmissão, distribuição e comercialização da energia, por essa razão a existência predominante de monopólio estatal.

Ao contrário, no modelo RE-SEB as empresas do segmento elétrico passaram por um processo de desverticalização, onde as mesmas tiveram suas atuações divididas por atividade, sendo geração/ transmissão, distribuição e comercialização. Com o novo modelo de 2004, a desverticalização foi mantida, acrescentando duas novas divisões, as empresas de importação e exportação, além disso as atividades de geração e transmissão também foram segregadas.

No que tange a natureza das empresas, no antigo modelo elas eram predominantemente estatais, ou seja, a gestão do setor elétrico era centralizada no setor público, a quem cabia a responsabilidade de geração, distribuição, transmissão e comercialização de energia. Além disso, como já mencionado, o segmento se caracterizava como monopólio estatal.

Enquanto que no modelo RE-SEB houve uma abertura para atuação da iniciativa privada, assim se buscou a competição onde era preciso e passou-se a regular apenas onde fosse necessário. Diante disso a ênfase maior das empresas privatizadas era a competição no ramo de geração e comercialização. No novo modelo de 2004, a coexistência entre empresas estatais e privadas foi preservada, mantendo a competição nos ramos referidos anteriormente e a posição de regulador do Estado sobre os setores de transmissão e distribuição, considerados monopólios naturais. (KESSLER, 2006)

A comercialização no modelo antigo abrangia apenas consumidores cativos, que são aqueles que adquirem energia de concessionárias específicas, e por essa via absorvem custos de possíveis erros de planejamento e gerenciamento dessa geração centralizada, por essa via assumem parte de custos na diferença de energia que foi programada e a de fato gerada. (BAJAY, 2015)

A novidade na comercialização trazida pelo RE-SEB foi a implantação do Mercado Atacadista de Eletricidade (MAE), onde a energia passou a ser comercializada por consumidores livres, que é aquele que tem a opção de fornecedores para comprar energia, observando a legislação aplicável. No entanto, para compra de energia para curto prazo a exclusividade de comercialização era de consumidores cativos. (BAJAY, 2015). 
No novo modelo algumas adaptações foram implantadas, em substituição ao MAE foi criado a Câmara de Comercialização de Energia Elétrica (CCEE) para gerenciamento da comercialização, além disso foi dado continuidade aos consumidores do tipo cativo e livre e novas regras também foram aplicadas. Para regular essas regras tarifárias, tipos de consumidores e contratos, foi desenvolvido um novo tipo de comercialização: ambiente livre e regulado.

O novo modelo adotou duas esferas de comercialização, o Ambiente de Contratação Livre (ACL) e Ambiente de Contratação Regulada (ACR). O primeiro, ACL, tem a participação dos setores de geração, comercialização, consumidores livres e cativos. Já no ACR, participam os setores de geração, distribuição e comercialização. No entanto, as comercializadoras têm as negociações restringidas aos leilões de energia existentes para ajuste ou modalidade A-1 (contratos de 5 a 15 anos).

A contratação de energia pode-se dar por livre negociação entre os compradores e vendedores no ACL. Já no ACR a contratação se dar através de leilões de energia promovidos pela Câmara de Comercialização de Energia Elétrica (CCEE) e os contratos são regulados pela Agência Nacional de Energia Elétrica (ANEEL). Disso são espelhados os tipos de contratos, que no primeiro ambiente pode ser acordado entre as partes que negociam a compra/ venda de energia, e já no segundo ambiente o contrato obrigatoriamente deve ser regulado pela ANEEL. (CCEE, 2015)

Além disso, de acordo com o ambiente no qual a comercialização é realizada, os preços das tarifas sofrem variação, pois, no ACL, onde a comercialização é livre, o preço também é livremente negociado, existindo assim a competitividade, enquanto que no ACR, os preços são estabelecidos e contratados através de leilões e licitações pela menor tarifa.

Os leilões de compra de energia elétrica consistem na contratação da energia destinada à cobertura do consumo existente e também futuro, a demanda de energia elétrica é estabelecida por distribuidores. Cabe frisar que os leilões de reserva têm como objetivo contratar energia adicional ao Sistema Interligado Nacional (SIN), visando "aumentar a garantia de suprimento e reduzir custos operacionais do SIN. Sua demanda é determinada pelo poder concedente, responsável pela segurança energética do sistema". (EPE e MME, 2009, p. 15)

Ademais, chama-se a atenção para o fato de que a estratégia do leilão de energia diminui o risco do empresário na medida em que realiza contrato em longo prazo, garantindo tempo para retorno de capital.

Acrescenta-se também a adaptação do mercado de curto prazo, trazido inicialmente pelo projeto RE-SEB, "nesse mercado se realiza os ajustes entre os volumes contratados e os volumes medidos de energia". Além disso, a obrigatoriedade na contratação no modelo RE-SEB era de contratar 85\% e depois 95\% do mercado estabelecido em resoluções da ANEEL - no novo modelo passou a ser de totalidade da demanda por parte das distribuidoras e dos consumidores livres do mercado estabelecido em lei e detalhada em Decreto. (CCEE, 2015).

Nesse contexto, torna-se básico conhecer como o setor elétrico se comportou diante das mudanças implementadas até o novo modelo de 2004. Na Figura 2 é apresentado dados da matriz de geração elétrica e a relação entre o consumo e oferta, ambos os dados são expressos em Gwh.

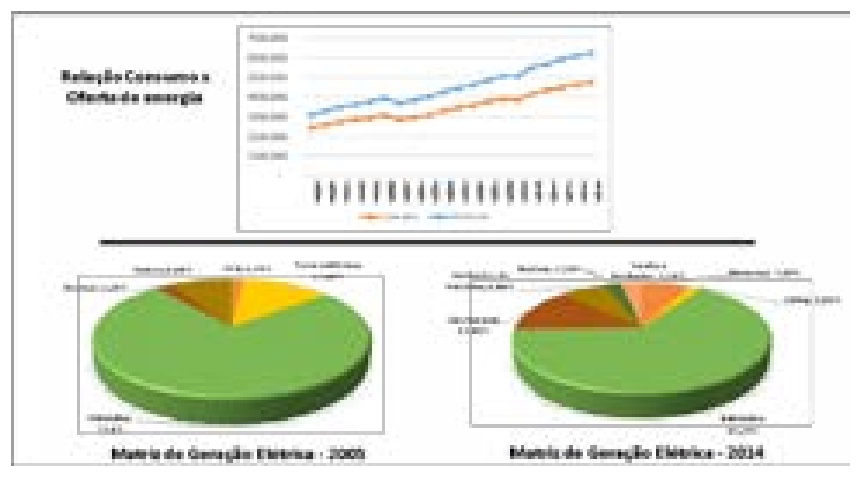

Figura 2: Relação consumo x oferta e Matriz de Geração Elétrica (Gwh)

Fonte: Elaboração própria a partir de dados da EPE (2015) e BEN (2015). 
$\mathrm{Na}$ Figura 2, o gráfico estilo em linhas descreve a relação entre o consumo sobre a oferta de eletricidade no Brasil. Observa-se a partir dele que de $2004 \mathrm{em}$ diante o hiato entre consumo e oferta cresceu, ou seja, o sistema elétrico nacional aumentou sua capacidade de atender a demanda. Essa relação, entre 1995 a 2014, corresponde a 122\% de elevação no spread entre a capacidade da oferta em corresponder a demanda.

Um ponto importante que se deve considerar nessa análise foi a diversificação da matriz elétrica no mesmo período. Nos gráficos em formato pizza é possível visualizar essa diversificação, onde se verifica uma redução da participação da fonte hidráulica, que no ano de 2005 contava com 74,6\% da matriz e passou para 65,2\% no ano de 2014. Já no que tange as novas fontes alternativas de energia, como biomassa e eólica, que não compunham a matriz em 2004, passaram a respondem em 2014 por 7,3\% e $2 \%$ respectivamente. Fato importante que contribuiu para essa inserção das fontes de biomassa e eólica foi o Programa Proinfa, que lançou incentivos à produção elétrica a partir dessas fontes.

Diante disso, nota-se que a partir do ano de 2004 as condições proporcionadas para a expansão do setor elétrico condicionaram a uma maior segurança na oferta de energia elétrica no país, além de um ambiente regulatório mais sólido e confiável. Por essa via, a expansão e investimentos nesse segmento condicionam possibilidades de crescimento do sistema.

Por fim, é notável que as modificações e inserções no novo modelo proposto para o setor elétrico no ano de 2004, tornou o segmento capaz de equilibrar a coexistência entre os capitais público e privado, promovendo ainda um ambiente competitivo. Essas medidas proporcionaram outras implementações relevantes nos anos posteriores que serão apresentadas adiante.

\section{Eventos posteriores:}

\section{Início dos leilões de energia renovável em 2007 a medida provisória 579 de 2012}

Conforme apresentado anteriormente, as reformas no ambiente de comercialização de energia elétrica e as novas regras estabelecidas no Ambiente de Contratação regulada (ACR) promoveram a implementação de leilões para a compra de energia no curto e longo prazo. O primeiro leilão foi realizado no ano de 2005, segundo a EPE (2015) foram contratados 49 empreendimentos de geração elétrica, sendo 20 novos empreendimentos entre termelétricas e hidrelétricas, todas com o prazo de até cinco anos para iniciar as operações, ou seja, início da produção de energia para o ano de 2010, o valor financeiro do leilão foi de R $\$ 68,4$ bilhões.

Nos anos de 2006 mais dois leilões de compra de energia foram realizados, ambos negociaram usinas do tipo termelétrica e hidrelétrica e o prazo para o início das operações foi de três e cinco anos, configurados como sendo empreendimento A-3 e A-5 respectivamente. O primeiro leilão neste ano negociou $\mathrm{R} \$ 45,6$ bilhões e o ano para operar sendo 2009 , e o outro um valor financeiro de $\mathrm{R} \$ 27,75$ bilhões e a entrada em operação programada para 2011. Esse segundo leilão representou a contratação de 99,6\% da demanda de energia projetada para todo o ano de 2011. (EPE, 2015)

Apesar disso, alguns autores alertam que mesmo diante dos esforços de contratação de novos empreendimentos geradores de energia elétrica a demanda por eletricidade poderia atingir nos anos seguintes marcas superiores a oferta. Em sua tese, Castro e Bueno (2007) pontuam a atenção de dois pontos, o primo e o secondo. Segundo eles, primo seria a elevação da demanda provinda pelo crescimento estimulado pelo Programa de Aceleração do Crescimento (PAC) e secondo como sendo um possível desequilíbrio entre elevação expressiva da demanda da indústria por gás natural e a insuficiente produção. Essa sendo também fonte de geração elétrica nas usinas termoelétricas. 
Em atenção à necessidade de diversificação da matriz elétrica nacional, foi iniciado no país incentivo à produção de energia elétrica por outras fontes, sobretudo as renováveis. Assim sendo, no ano de 2007 foi realizado o primeiro leilão de "energia limpa", cuja fontes era as pequenas centrais hidrelétricas $(\mathrm{PCH})$ e termoelétricas por biomassa com uso do bagaço da cana de açúcar e criadouros avícolas. Nesse leilão, o volume negociado foi de R \$4,189 bilhões e o total de 638,64 MW de energia proveniente de novas usinas, sendo, 511,9 MW de biomassa (bagaço cana de açúcar), $30 \mathrm{MW}$ biomassa (criadouros avícolas) e 96,74 MW de pequenas centrais hidrelétricas. O prazo para iniciar a produção da energia contratada foi o ano de 2010. (EPE, 2015)

Após início dos leilões de energia por fontes renováveis em 2007, outras fontes passaram a ser inclusas na oferta, como a fonte eólica, essa possuindo grande potencial instalado nas regiões sul e nordeste do Brasil. Contudo, faz-se necessário ressaltar que embora o acréscimo de MW por fontes renováveis na matriz elétrica brasileira, além de representar estratégia de longo prazo, e segurança energética para o país na medida em que reduz dependência das hidrelétricas, a conclusão desses empreendimentos enfrentou, e ainda enfrenta, grandes obstáculos, sobretudo nas linhas de transmissões que ligam a geração ao Sistema Interligado Nacional (SIN), a responsabilidade da viabilização das linhas de transmissão é do setor público federal.

Ainda assim, é salutar frisar que a matriz elétrica brasileira alcançou alguma redução na dependência das hidrelétricas entre os anos de 2004 a 2014, período regulado pelo novo modelo do setor elétrico. No ano de 2005 a fonte hidráulica representava cerca de 74,6\% da matriz elétrica nacional, já no ano de 2014 essa participação caiu para 65,20\%. No mesmo período, as fontes renováveis de biomassa e eólica elevaram 7,4\% e 2,0\% respectivamente. (BEN, 2015)

Durante esse período apresentado da diversificação da matriz elétrica, o mesmo foi marcado também pela quantidade de decretos e medidas provisórias implementadas no setor elétrico. Entre os anos de 2004 a início de 2015 foram 36 medidas de regulação. A que trouxe maior impacto ao setor foi a MP 579 de 2012, essa medida teve por objetivo repassar redução tarifaria ao consumidor final. Essa modicidade tarifaria seria proveniente da desoneração de certos encargos do setor, renovações de concessões de geração, transmissão e distribuição de energia e o aporte acima de 3 bilhões na Conta do Desenvolvimento Energético (CDE) provenientes do Tesouro Nacional. (COSTELLINI E HOLLANDA, 2014)

Alguns pontos negativos sobre as empresas de geração e transmissão foram mais evidentes. $O$ fato de renovar as concessões sobre a antecipação dos vencimentos dos contratos previstos inicialmente para 2015 até 2017, condicionou no preço da energia uma redução de aproximadamente $\mathrm{R} \$$ 95,00/ MWh para R \$30,00/MWh. Em situação semelhante, as concessionárias de transmissão passariam a ser remuneradas por uma tarifa que contemplaria apenas custos de operação e manutenção, ocasionando efeito negativo no fluxo de caixa dessas empresas. (CASTRO et al, 2013)

O impacto no fluxo de caixa sofrido por parte das empresas ocasionou inclusive redução dos preços de seus ativos no mercado de capitais, sobretudo as estatais Eletrobrás, Cesp e Cemig. Costellini e Hollanda (2014), ponderam ainda que a crise no setor elétrico nos anos de 2013 e 2014 em alguma medida sofreu reflexos da MP 579, tal crise configurou-se na situação do fluxo de caixa das distribuidoras concessionárias, que contou com o apoio financeiro do tesouro nacional. As autoras em tela alertam para as questões conjunturais já existentes no segmento que intensificaram a crise de 2013 e 2014, e destacam a necessidade do planejamento estratégico de longo prazo.

Diante disso, conclui-se que o planejamento inserido no setor elétrico no decorrer dos anos, sobretudo a partir do novo modelo adotado a partir do ano de 2004, se constitui como medida relevante que contribuiu para o desenvolvimento do segmento, e necessita ser aperfeiçoada de acordo com as necessidades e novas demandas que o setor elétrico apresenta e que tais medidas apresentem um feixe de continuidade na atuação. 


\section{CONSIDERAÇÕES FINAIS}

Neste artigo foram analisados os principais eventos ocorridos no setor de energia elétrica brasileiro e a expansão do segmento ao longo do período, evidenciando os principais desafios para o crescimento continuado do setor elétrico nacional.

O estudo cumpriu com o objetivo geral estabelecido de analisar o processo de reestruturação e a expansão do setor elétrico brasileiro entre os anos de 1995 a 2014, identificando, a partir das relações estabelecidas entre os principais eventos do período, que as estratégias adotadas no país para assegurar a expansão continuada do setor elétrico, em certa medida, têm sido eficientes na série temporal analisada.

No que tange às mudanças no setor elétrico a partir do ano de 1995, com a adoção do modelo Restruturação do Setor Elétrico Brasileiro (RE-SEB), constatou-se a incapacidade de investimento estrutural por parte do setor público no início da década de 1990, esse fato culminou na abertura do setor para atuação privada possibilitando por essa via expansão do setor elétrico. Ademais, a desverticalização das empresas promoveu maior dinamismo ao segmento, nessa fase o planejamento ainda era feito de maneira indicativa pelo Conselho Nacional de Política Energética (CNPE).

Nesse período foram criados a Agência Nacional de Energia Elétrica (ANEEL) e o Operador Nacional do Sistema Elétrico (ONS), que promoveram a regulação do setor diante da atuação privada, de modo a se balancear os interesses dos agentes e consumidores pelo serviço de energia elétrica. Além disso, fato importante foi também a criação do Mercado Atacado de Energia (MAE), que possibilitou a competição na comercialização com consumidores livres.

Constatou-se que as medidas implementadas possibilitaram competitividade no setor, contudo as dificuldades enfrentadas no início da década seguinte evidenciaram que o objetivo do projeto RE-SEB de melhor eficiência e qualidade do serviço não estava sendo integralmente alcançado. Novas melhorias foram observadas a partir do ano de 2004 com a lei 10.848, que determinou nova regulação e regras ao setor elétrico.

A partir desse novo modelo o conceito de planejamento de longo prazo foi incluído para o setor elétrico, a criação a Empresa de Pesquisa Energética (EPE) se configurou como um avanço importante no que tange o planejamento, o órgão é responsável pelo planejamento energético nacional e avalia permanentemente a segurança do suprimento de energia elétrica

Conforme análise, constatou-se que entre as medidas do novo modelo as mudanças no ambiente de comercialização trouxeram maior eficiência para o segmento, pois a possibilidade de coexistência entre ambiente de contratação livre e regulada trouxe maior dinamismo a comercialização de energia, garantindo a administração dos preços, mas também permitindo a competitividade.

Em linhas gerais, foi observado que os principais desafios para o crescimento continuado do setor elétrico no Brasil perpassa questões regulatórias, que embora tenha se tornado sólida após 2004, constatou-se nos últimos anos a fragilidade de exposição da iniciativa privada a medidas provisórias estabelecidas pelo governo, elevando as incertezas.

Outro fato importante é a necessidade de diversificação da matriz de geração elétrica, uma vez que o Brasil ainda tem dependência da fonte hidráulica acima de 50\% do total da oferta por fonte. As energias renováveis cumprem um importante papel nesse tocante e devem ser incentivadas novas tecnologias de aprimoramento para elevar a competitividade frente às demais fontes de energia mais convencionais no país.

Por fim, como averiguado no desenvolvimento desta pesquisa, a expansão do setor elétrico após 1995 apresentou comportamento crescente com spread entre oferta e consumo, durante quase todo o período, confortável. Exceções para o período de $2001 \mathrm{com}$ a crise que adotou o racionamento de energia, e 2008 devido cenário econômico da mesma época. 
Dessa forma, pode-se concluir que os modelos implantados no processo de reestruturação do setor elétrico nacional alcançaram resultados significativos e de avanço ao segmento elétrico. Todavia faz-se necessário continuidade do planejamento em longo prazo para minimizar as incertezas que ainda existem no setor e ampliar a expansão e segurança energética no país.

\section{REFERÊNCIAS}

1. ANEEL, Agência Nacional de Energia Elétrica. Missão e Visão. Disponível em: http:// www.aneel.gov.br/. Acesso em: agosto, 2015.

2. BAJAY, Sergio Valdir. Uma revisão crítica do atual planejamento da expansão do setor elétrico brasileiro. Revista Brasileira de Energia, Vol. 9, No. 1. 2015.

3. BEN, Balanço Energético Nacional. Séries históricas completas. Disponível em: $<$ https:// ben.epe.gov.br/ >. Acesso: novembro de 2015.

4. BNDES, Banco Nacional de Desenvolvimento. Disponível em: < http://www.bndes. gov.br>. Acesso: outubro de 2015.

5. CASTRO, Nivalde José de; BUENO, Daniel. Os Leilões de Energia Nova: Vetores de Crise ou de Ajuste entre Oferta e Demanda. Economia \& Energia, Rio de Janeiro, ano XI, n. ${ }^{\circ}$ 63, p. 2944, Agosto-Setembro, 2007.

6. CASTRO, Nivaldo J.; BRANDÃO, Roberto. DANTAS, Guilherme; ROSENTAL, Rubens. O Processo de Reestruturação do Setor Elétrico Brasileiro e os Impactos da MP 579. Texto para Discussão do Setor Elétrico, No 51. Rio de Janeiro: 2013.

7. CCEE, Câmara de Comercialização de Energia Elétrica. Disponível em: <http://www. ccee.org.br>. Acesso: outubro de 2015.

8. CHIGANER, Luis; RIBEIRO, Acácio Magno; MELLO, João Carlos C.B. Soares de; BIONDI NETO, Luiz. A Reforma do Setor Elétrico Brasileiro Aspectos Institucionais. Disponível em: <http://www.nipeunicamp.org.br/agrener/anais/2002/0123.pdf>. Acesso em: 2015

9. CORREIA, Tiago B.; MELO, Elbia; COSTA, Agnes M., SILVA, Adriano J. Trajetória das Reformas Institucionais da Industria Elétrica Brasileira e Novas Perspectivas de Mercado. Revista Economia. 2006.

10. COSTELLINI, Clara; HOLLANDA, Lavinia. Setor Elétrico: da MP 579 ao pacote financeiro. Informativo de Energia. FGV Energia, 2014. 
11. EPE, Empresa de Pesquisa Energética. Institucional. Disponível em: < http://www.epe. gov.br>. Acesso em: outubro, 2015.

12. . MME, Ministério de Minas e Energia. Proposta para a Expansão da Geração Eólica no Brasil. NOTA TÉCNICA PRE 01/2009-r0. Brasília: 2009.

13. GOLDEMBERG, J.; MOREIRA, J. R. Política Energética no Brasil. Estudos Avançados, São Paulo, v19, n.55, p.215-228, set-dez. 2005.

14. GOTTEMS, Leila B. D. Análise da política de atenção primaria à saúde desenvolvida no Distrito Federal: a articulação entre o contexto político, os problemas, as alternativas e os atores na formação da política de saúde (1979 a 2009). 2010. 285 f. Tese (Doutorado em Administração) Universidade de Brasília, Brasília.

15. GUERRA, Lenin Cavalcanti Brito. O processo de formulação do programa universidade para todos: atores, coalizões e interesses. Tese (Doutorado em Administração) - Universidade Federal do Rio Grande do Norte, Natal, 2015.

16. KESSLER, Marcos Rodolfo. A regulação econômica no setor elétrico brasileiro: teoria e evidencias. 2006. 170 f. Dissertação (Mestrado em Economia0 - Universidade Federal do Rio Grande do Sul, Porto Alegre.

17. KLERING, Roque Luiz; PORSSE, Melody de C. S.; GUADAGNINC, Luiz Alberto. Novos Caminhos da Administração Pública Brasileira. Análise - Revista Acadêmica da FACE. Porto Alegre, v. 21, n. 1, p. 4-17, jan/jun, 2010.

18. MME, Ministério de Minas e Energia. Comitê de Monitoramento do Setor Elétrico. Disponível em: < http://www.mme.gov.br/>. Acesso em: outubro, 2015).

19. OLIVEIRA, Fabrício Augusto de. Política econômica, estagnação e crise mundial: Brasil, 1980- 2010. Rio de Janeiro: Azougue, 2012.

20. OLIVEIRA, José Antônio P. Desafios do planejamento em políticas públicas: diferentes visões e práticas. Rev. Adm. Pública, vol.40, n.2, pp.273-287, 2006.

21. ONS, Operador Nacional do Sistema Elétrico. Disponível em: <http://www.ons.org.br/ home>. Acesso em: outubro, 2015.

22. RUA, Maria das Graças. Políticas públicas. 2. ed. Florianópolis: Departamento de Ciências da Administração/UFSC, 2012 
23. SILVA, Bruno Gonçalves da. Evolução do setor elétrico brasileiro no contexto econômico nacional: uma análise histórica e econométrica de longo prazo. Dissertação (Mestrado em Ciências/ Energia), Universidade de São Paulo, São Paulo, 2011.

24. SROUR, Sandra. A reforma do estado e a crise no setor de energia elétrica: uma visão crítica do caso brasileiro. Dissertação (Administração Pública), Fundação Getúlio Vargas, Rio de Janeiro, 2005.

25. TEIXEIRA, Elenaldo Celso. O Papel das Políticas Públicas no Desenvolvimento Local e na Transformação da Realidade. Salvador: AATR; 200

26. TONI, Jackson de. A retomada do planejamento estratégico governamental no Brasil: novos dilemas e perspectivas. VII Congresso CONSAD de Gestão Pública. Brasília, 2014. 